\title{
Germinação in vitro de sementes e parâmetros morfofisiológicos de microestacas de Tabernaemontana catharinensis A. DC.
}

\author{
Marcelo Vielmo Afonso', Juçara Terezinha Paranhos², \\ Luciane Almeri Tabaldi ${ }^{2}$ \& Hilda Hildebrand Soriani ${ }^{3}$
}

\author{
IInstituto Federal Farroupilha, Campus Panambi, Coordenação Geral de Ensino, Laboratórios, Rua Erechim, 860, CEP 98280-000, \\ Panambi, RS, Brasil. marcelovielmo@yahoo.com.br \\ 2Universidade Federal de Santa Maria, Departamento de Biologia, Av. Roraima, 1000, CEP 97105-900, Santa Maria, RS, Brasil, \\ jtparanhos@gmail.com, lutabaldi@yahoo.com.br \\ ${ }^{3}$ Universidade Federal de Santa Maria, Campus Frederico Westphalen, Departamento de Engenharia Florestal, \\ Linha 7 de setembro s/n, BR 386 Km 40, CEP 98400-000, Frederico Westphalen, RS, Brasil, hildasoriani@gmail.com
}

Recebido em 15.IV.2016

Aceito em 24.V.2018

DOI 10.21826/2446-8231201873105

\begin{abstract}
RESUMO - O objetivo deste estudo foi avaliar a germinação in vitro de sementes e parâmetros morfofisiológicos de microestacas de Tabernaemontana catharinensis A.DC. Nos bioensaios de germinação, sementes foram imersas em soluções de 0,$0 ; 300$ e $600 \mathrm{mg} \mathrm{L}^{-1} \mathrm{GA}_{3}$ por 24 ou $48 \mathrm{~h}$. As plântulas provenientes da germinação in vitro foram doadoras de microestacas, e estas inoculadas em meio de cultivo MS completo suplementado com 0,0 ; 1,$0 ; 2,0$ e 4,0 $\mathrm{mg} \mathrm{L}^{-1}$ de AIB. O uso de GA não favorece maiores taxas de germinação em sementes de T. catharinensis, sendo a velocidade de germinação afetada negativamente em sementes expostas ao $\mathrm{GA}_{3}$ por um período maior (48h). A rizogênese em microestacas de $T$. catharinensis pode ser induzida sem a necessidade de fitorreguladores. No entanto, os parâmetros morfofisiológicos podem ser maximizados com a adição de AIB ao meio de cultura, demonstrando que o uso de AIB potencializa a produção de microestacas assépticas de T. catharinensis.
\end{abstract}

Palavras-chave: ácido giberélico, ácido indolbutírico, cobrina

\begin{abstract}
In vitro seed germination and morphophysiological parameters of Tabernaemontana catharinensis A. DC. microcuttings. The aim of this study was to evaluate in vitro seed germination and the morphophysiological parameters of Tabernaemontana catharinensis microcuttings. In the germination bioassays, the seeds were immersed at solutions of $0.0 ; 300$; and $600 \mathrm{mg} \mathrm{L}^{-1} \mathrm{GA}_{3}$ for 24 or $48 \mathrm{~h}$. The seedlings from in vitro germination were used to produce microcuttings, which were inoculated in MS growth medium supplemented with $0.0 ; 1.0 ; 2.0 ;$ and $4.0 \mathrm{mg} \mathrm{L}^{-1}$ of IBA. The use of $\mathrm{GA}_{3}$ did not lead to higher seed germination rates in $T$. catharinensis and the germination rate was negatively affected in seeds exposed to $\mathrm{GA}_{3}$ for longer periods (48h). Rhizogenesis of $T$. catharinensis microcuttings can be induced without the need for phytoregulators. However, the morphophysiological parameters can be improved with the addition of IBA to the growth medium, showing that the use of IBA potentiates the production of aseptic microcuttings of $T$. catharinensis.
\end{abstract}

Keywords: gibberellic acid, indolebutyric acid, cobrina

\section{INTRODUÇÃO}

O número limitado de estudos dos principais processos básicos da germinação das sementes de plantas lenhosas e nativas tem dificultado a realização de programas de reflorestamento e melhoramento genético com espécies de potencial medicinal (Nascimento et al. 2007). Devido aos efeitos dos promotores de crescimento na germinação das sementes e crescimento e desenvolvimento das plantas, muitos compostos e combinações desses produtos têm sido pesquisados com a finalidade de resolver problemas do sistema de produção e melhorar qualitativa e quantitativamente a produtividade (Castro \& Vieira 2003).

Tabernaemontana catharinensis A. DC. (Apocynaceae) é uma espécie nativa do Rio Grande do Sul, sendo também encontrada na Argentina, Paraguai e Bolívia (Pereira et al. 2008). É uma planta pioneira medindo de 3 a $8 \mathrm{~m}$ de altura, popularmente conhecida como "cobrina", "jasmimcata-vento", "leiteira-de-dois-irmãos" e "casca-de-cobra"
(Quinet \& Andreata 2005). O chá ou a infusão das folhas e cascas são utilizados na medicina popular como antídoto para picadas de cobra, para aliviar dor de dente, tratamento de feridas, herpes, tumores e ainda como hemostática, hipotensora, cardiotônica e também como vermífugo (Pereira et al. 2005).

A espécie é rica em flavonoides, saponinas, terpenos, alcaloides e esteroides (Bélo et al. 2009), possuindo capacidade bioinseticida (Ferreira et al. 2001) e atividade antioxidante devido ao acúmulo de rutina, quercetina e ácido clorogênico (Piana et al. 2014). A espécie, além de possuir potencial ornamental, é indicada para reflorestamentos mistos destinados à recuperação de mata nativa (Sobral et al. 2006).

A busca por mecanismos para acelerar e uniformizar a germinação das sementes para obtenção de plântulas com alta qualidade genética e fitossanitária são imprescindíveis e constituem o ponto de partida para o estabelecimento de povoamentos comerciais produtivos e para a conservação 
e estocagem de germoplasma, especialmente espécies consideradas de interesse medicinal e florestal (Galdiano et al. 2012). No entanto, a falta de informações para obtenção de mudas de espécies nativas e, em alguns casos, a falta de viabilidade de suas sementes, indicam o uso de técnicas biotecnológicas como alternativa na sua multiplicação (Bortolini et al. 2009).

Nesse sentido, a germinação in vitro para algumas espécies permite maior germinabilidade das sementes, possivelmente em função das condições do cultivo in vitro oferecer maior controle do que as condições de viveiro (Noleto \& Silveira 2004). Além disso, as plântulas obtidas a partir da germinação das sementes in vitro podem ser utilizadas para estudos alternativos que visem o desenvolvimento de protocolos, para servir de base para outras técnicas biotecnológicas (Xavier et al. 2009).

Desse modo, este trabalho teve como objetivo avaliar a germinação in vitro de sementes de Tabernaemontana catharinensis e o enraizamento, produção de biomassa e conteúdo de pigmentos de microestacas oriundas das plântulas obtidas in vitro.

\section{MATERIAL E MÉTODOS}

\section{Bioensaios de germinação}

Frutos de Tabernaemontana catharinensis foram coletados no terço médio lateral de cinco matrizes com cerca de 4,0 m de altura e localizadas em remanescente vegetal, no município de Ijuí, região Noroeste do Rio Grande do Sul (28 26'07'S e 5357'50'O), no mês de junho de 2015. No Laboratório de Cultura de Tecidos Vegetais da Universidade Federal de Santa Maria, Santa Maria, RS, as sementes foram submetidas ao processo de secagem natural sobre bandeja com fundo de tela por cinco dias. Em câmara de fluxo laminar as mesmas foram desinfestadas em álcool $70 \%$ por 30 segundos, hipoclorito de sódio a $2,5 \%$ por 20 minutos e após, enxaguadas três vezes em água destilada e esterilizada. As sementes foram imersas em soluções aquosas de ácido giberélico $\left(\mathrm{GA}_{3}\right)$ nas concentrações de 0,$0 ; 300$ e $600 \mathrm{mg} \mathrm{L}^{-1}$, em dois regimes de tempo, 24 e $48 \mathrm{~h}$. Para as soluções aquosas de ácido giberélico, o $\mathrm{GA}_{3}$ em câmara de fluxo laminar, foi dissolvido em três gotas de álcool 70\% e após, acrescentado água destilada e autoclavada.

Após a imersão, em câmara de fluxo laminar, as sementes foram inoculadas em tubos de ensaio medindo $25 \times 150 \mathrm{~mm}$ (uma semente por tubo) contendo $15 \mathrm{~mL}$ de meio de cultura MS (Murashige \& Skoog 1962), com $30 \%$ dos sais minerais, $15 \mathrm{~g} \mathrm{~L}^{-1}$ de sacarose, $1,0 \mathrm{~mL} \mathrm{~L}^{-1}$ de fungicida Maxim ${ }^{\circledR}$ (princípio ativo fludioxonil) e 0,3 $\mathrm{mg} \mathrm{L}^{-1}$ de bactericida Chlortetracycline. Estes produtos foram utilizados pelo fato das espécies arbóreas nativas apresentarem, normalmente, diversidade de microrganismos contaminantes endógenos, os quais não são eliminados pela desinfestação. $\mathrm{O}$ pH do meio de cultura foi ajustado para $5,8 \pm 0,1$ com $\mathrm{NaOH} 0,1 \mathrm{~N}$ ou $\mathrm{HCl} 0,1 \mathrm{~N}$ e após semisolidificado com $6,0 \mathrm{~g} \mathrm{~L}^{-1}$ de ágar em pó bacteriológico puro e esterilizado em autoclave a $1,0 \mathrm{~atm}, 120^{\circ} \mathrm{C}$, por 20 minutos.

Os tubos foram fechados com papel alumínio e as culturas foram transferidas para sala de crescimento com temperatura de $25 \pm 1{ }^{\circ} \mathrm{C}$ e fotoperíodo de 16 horas (densidade de fluxo de fótons de $35 \mu \mathrm{mol} \mathrm{m}^{-2} \mathrm{~s}^{-1}$ fornecida por lâmpadas fluorescentes branca-frias).

$\mathrm{O}$ experimento foi em esquema bifatorial $3 \times 2$ (três concentrações de $\mathrm{GA}_{3}$ e dois tempos de imersão), totalizando seis tratamentos com quatro repetições por tratamento e 15 sementes por repetição, em delineamento inteiramente casualizado. As avaliações foram realizadas a cada três dias, até a estabilização da germinação em cada tratamento. Os parâmetros avaliados foram a percentagem de germinação $(\% \mathrm{G})$, conforme Labouriau \& Valadares (1976), sendo considerada geminada quando os cotilédones estavam totalmente livres acima do meio de cultivo, e o índice de velocidade de germinação (IVG), conforme Maguire (1962).

\section{Enraizamento in vitro de microestacas}

Plântulas com 90 dias de idade obtidas dos bioensaios da germinação das sementes foram doadoras de microestacas para o estudo de enraizamento in vitro. Microestacas de $4,0 \mathrm{~cm}$ de comprimento, contendo meristema apical e três pares de folhas, foram inoculadas em tubos de ensaio (mesmas dimensões do experimento anterior) contendo $15 \mathrm{~mL}$ de meio MS completo, suplementado com $30 \mathrm{~g}$ $\mathrm{L}^{-1}$ de sacarose, $100 \mathrm{mg} \mathrm{L}^{-1}$ de mio-inositol, $1 \mathrm{~g} \mathrm{~L}^{-1} \mathrm{de}$ carvão ativado e adicionado fungicida Maxim ${ }^{\circledR} 2,5 \mu 1 \mathrm{~L}^{-1}$, bactericida Chlortetracycline $0,15 \mathrm{mg} \mathrm{L}^{-1}, \mathrm{pH}$ do meio de cultura ajustado para 5,8 $\pm 0,1$ e semi-solidificado com $6,0 \mathrm{~g} \mathrm{~L}^{-1}$ de ágar antes da esterilização em autoclave. Aos meios foi adicionado ácido indolbutírico (AIB), testandose as concentrações 0,$0 ; 1,0 ; 2,0$ e $4,0 \mathrm{mg} \mathrm{L}^{-1}$, totalizando quatro tratamentos com quatro repetições por tratamento e sete explantes por repetição em delineamento experimental inteiramente casualizado.

As culturas foram mantidas nas mesmas condições do estudo de germinação e aos 30 dias após a inoculação, as avaliações foram realizadas obtendo-se a percentagem de enraizamento. Através de quatro microestacas por repetição foi obtida a massa fresca das raízes em balança analítica de precisão em miligramas (mg), comprimento das raízes, área superficial, volume e número de raízes primárias, através da digitalização com auxílio de um scanner Epson 11000 XL e analisadas com ajuda do Software WinRhizo Pro.

Para obtenção dos teores de pigmentos fotossintéticos nas folhas das microestacas enraizadas, o material vegetal foi macerado em acetona $80 \%$, determinando-se os teores de clorofilas $a, b$, clorofilas totais, relação clorofila $a / b$ e carotenoides $\left(\mathrm{mg} \mathrm{g}^{-1} \mathrm{MF}\right)$, por espectrofotometria de UV a 663, 645 e $480 \mathrm{~nm}$, conforme metodologia de Arnon (1949).

Os resultados foram submetidos à análise de variância, sendo as médias das variáveis dos experimentos comparadas pelo teste Scott-knott, a 5\% de probabilidade de erro, utilizando o aplicativo Sisvar (Ferreira 2008). 


\section{RESULTADOS E DISCUSSÃO}

Os resultados da análise de variância não demonstraram efeito significativo entre os tratamentos pelo teste de Scott-knott para a percentagem de germinação (Fig. 1). As concentrações de $\mathrm{GA}_{3}$ e tempos de imersão não influenciaram significativamente a germinação das sementes, ficando esta numa faixa de 68 a $83 \%$, não diferindo entre si.

Embora o ácido giberélico, considerado ativador enzimático endógeno, promove a germinação e sua aplicação exógena influencia o metabolismo protéico (Braun et al. 2010), os tratamentos sem $\mathrm{GA}_{3}$ (controles), independentemente do tempo de imersão, também responderam satisfatoriamente para percentagem de germinação.

O ácido giberélico promove a germinação, por influenciar o metabolismo proteico, podendo dobrar a taxa de síntese de proteínas das sementes favorecendo o alongamento celular, fazendo com que a raiz primária rompa os tecidos que restringem o seu crescimento (Braun et al. 2010). Entretanto, neste estudo, a presença de $\mathrm{GA}_{3}$ independentemente do tempo de imersão, não mostrou efeito na percentagem de germinação das sementes. Provavelmente, as sementes de Tabernaemontana catharinensis não possuem dormência intrínseca dependente deste fitorregulador ou estas sementes possuem adequado nível endógeno do mesmo.

Estes resultados também foram observados em outras espécies, de acordo com Sousa et al. (2002) a aplicação de ácido giberélico em sementes de porta-enxertos cítricos (Limoeiro-'Cravo'; Tangerineira-'Sunki'; Tangerineira'Cleópatra'; 'UFLAD-4' e 'UFLAD-5) também não surtiu efeito significativo sobre a germinação, tal fato foi atribuído a um adequado nível endógeno do referido hormônio nas sementes.

Para Dalastra et al. (2010), foi verificada que em sementes não incisas de nogueira-macadâmia (Macadamia integrifolia), houve redução na emergência das plântulas com a elevação da concentração de ácido giberélico, da ordem de $25,51 \%$, quando comparada a maior concentração (450 mg L ${ }^{-1}$ ) em relação ao tratamento controle. Scalon et al. (2006) também observaram que não houve efeito da aplicação de giberelina em tratamento pré-germinativo de sementes de jacarandá (Jacaranda mimosifolia). Segundo esses autores, as sementes provavelmente possuíam teores endógenos de giberelinas suficientes para a germinação.

Para a variável IVG houve diferença significativa entre os tratamentos (Fig. 2); sementes imersas por 24 horas em 300 e $600 \mathrm{mg} \mathrm{L}^{-1}$ de $\mathrm{GA}_{3}$, quando comparadas com àquelas imersas por 48 horas nas referidas concentrações mostraram maior velocidade de germinação. Além disso, sementes imersas em $600 \mathrm{mg} \mathrm{L}^{-1}$ de $\mathrm{GA}_{3}$ apresentaram menor IVG em relação as concentrações 0,0 e $300 \mathrm{mg} \mathrm{L}^{-1}$ de $\mathrm{GA}_{3}$ dentro do tempo de imersão de 48 horas.

Embora a aplicação de giberelina geralmente induza a uma maior rapidez na germinação de sementes observada nos primeiros dias de tratamento, culminando posteriormente

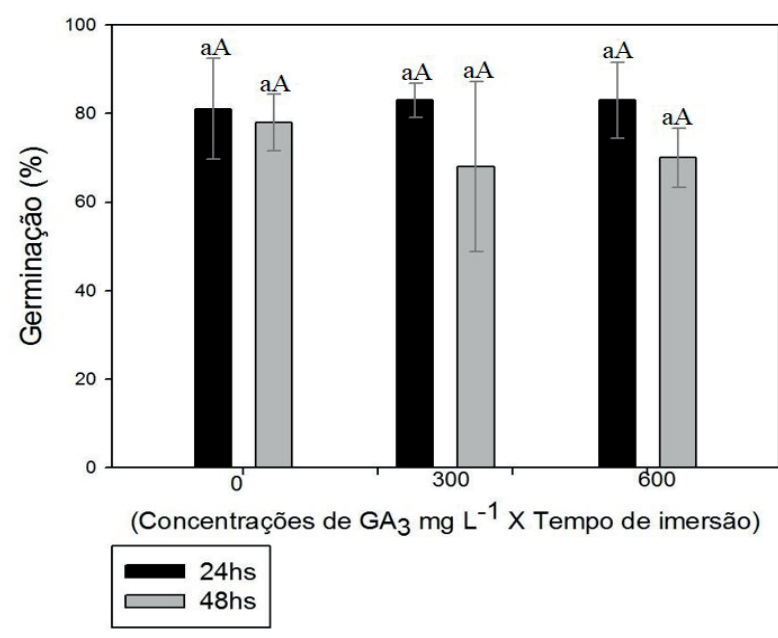

Fig. 1. Percentagem de germinação das sementes de Tabernaemontana catharinensis em condições in vitro. * Letras minúsculas diferentes indicam diferença significativa entre as concentrações de $\mathrm{GA}_{3}$ dentro do tempo de imersão. Letras maiúsculas diferentes indicam diferença significativa entre o tempo de imersão dentro da mesma concentração de $\mathrm{GA}_{3}$, pelo teste de Scott-knott a 5\% de probabilidade.

em um maior vigor (Aragão et al. 2006), neste trabalho não foi observado esta tendência, evidenciando uma redução no IVG nas sementes expostas a um maior tempo de imersão (48h) nas concentrações de 300 e $600 \mathrm{mg} \mathrm{L}^{-1}$ de $\mathrm{GA}_{3}$, quando comparado com sementes imersas nas referidas concentrações por 24h. Estes resultados também foram observados por Stein et al. (2007) na germinação in vitro de sementes de ingazeiro (Inga vera). Neto et al. (2007) observaram que a embebição em $200 \mathrm{mg} \mathrm{L}^{-1}$ de $\mathrm{GA}_{3}$ proporcionou aumento significativo do IVG, indicando efeito positivo desta substância na melhoria

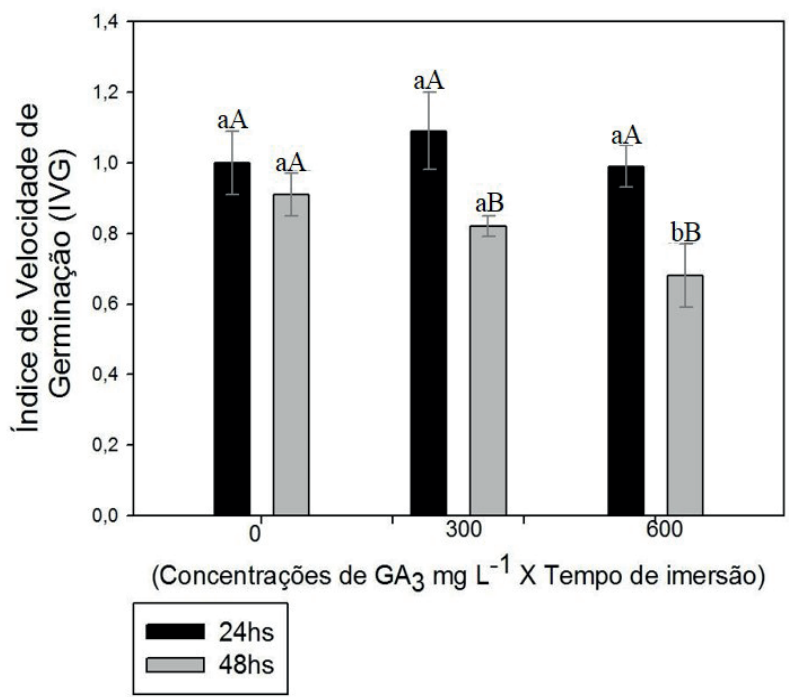

Fig. 2. Índice de velocidade de germinação das sementes de Tabernaemontana catharinensis em condições in vitro. * Letras minúsculas diferentes indicam diferença significativa entre as concentrações de $\mathrm{GA}_{3}$ dentro do tempo de imersão. Letras maiúsculas diferentes indicam diferença significativa entre o tempo de imersão dentro da mesma concentração de $\mathrm{GA}_{3}$, pelo teste de Scott-knott a 5\% de probabilidade. 


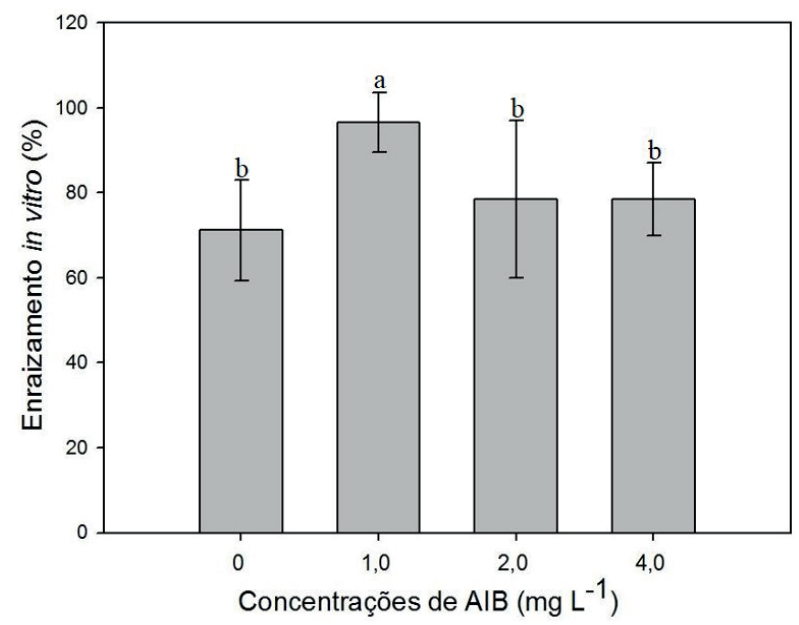

Fig. 3. Percentagem de enraizamento das microestacas de Tabernaemontana catharinensis em diferentes concentrações de AIB. *Médias seguidas de mesma letra não diferem entre si pelo teste de Scott-Knott a 5\% de probabilidade.

do desempenho das sementes de jenipapeiro (Genipa americana), evidenciando que cada espécie apresenta um comportamento.

Ainda, suplementações com fitorreguladores de crescimento podem causar efeito inibidor devido à ocorrência de sinergismo entre as concentrações aplicadas e a quantidade endógena de giberelina existente em sementes (Scalon et al. 2006). Essa inibição pode ocorrer devido à toxidez causada pelo excesso do fitorregulador no meio de cultura, ou pelo prolongado período de tempo em que a semente permanece exposta a ele, podendo provocar alterações fisiológicas e morfológicas (Vicente et al. 2009).

No enraizamento de microestacas houve efeito das diferentes concentrações de AIB na percentagem de microestacas enraizadas (Fig. 3). Maior percentagem de enraizamento foi observada na concentração de 1,0 $\mathrm{mg} \mathrm{L}^{-1}(96 \%)$, diferindo dos demais tratamentos. Nas concentrações de 0,$0 ; 2,0$ e 4,0 $\mathrm{mg} \mathrm{L}^{-1}$ de AIB as percentagens de enraizamento não diferiram, apresentando uma faixa de 71 a $78 \%$ de microestacas enraizadas.

As auxinas controlam uma grande variedade de processos implicados no desenvolvimento das plantas, entre eles a iniciação de novos meristemas de raízes, apresentando maiores efeitos na formação de raízes adventícias (Rocha et al. 2007). Dentre as auxinas, o AIB tem apresentado maior eficiência no enraizamento, no entanto, a utilização do regulador de crescimento bem como as concentrações ótimas a serem utilizadas é específica para cada situação (Xavier et al. 2009). A ação das auxinas ocorre, inicialmente, em nível celular nos meristemas primário e secundário, estimulando a divisão celular e o subsequente alongamento das células, sendo que essa ação inicial das auxinas culmina com a formação das raízes (Ford et al. 2002).

Altas taxas de enraizamento encontradas neste trabalho, acima de $70 \%$, incluindo no meio de cultura sem AIB, podem caracterizar alto vigor das microestacas, condicionado a fatores como reservas nutricionais adequadas, status hídrico ótimo, sem aparente condição de estresse. Além disso, esses resultados podem indicar juvenilidade do material utilizado e balanço hormonal endógeno proporcionados pelas condições de cultivo in vitro, induzindo a formação de raízes adventícias sem a necessidade do uso de fitorreguladores (Xavier et al. 2009).

Estacas apicais, geralmente utilizadas na microestaquia, são mais propensas à formação de raízes devido ao grau de maturação fisiológica e de lignificação menor. Acrescentase que as auxinas são sintetizadas principalmente em regiões de crescimento ativo, como gemas terminais e primórdios foliares, contribuindo para elevação dos níveis endógenos desse fitorregulador nas estacas apicais, refletindo em maior potencial de enraizamento (Xavier et al. 2009, Borges et al 2011). Silva et al. (2010), estudando a propagação da espécie arbórea Calophyllum brasiliense através de miniestacas, utilizando propágulos juvenis oriundos de mudas produzidas por sementes, relataram que não foi necessário o uso de reguladores vegetais para o enraizamento.

Dados de massa fresca, comprimento, área superficial, volume e número de raízes primárias são apresentados na tabela 1 e ilustrados na figura 4. Os resultados indicam um efeito significativo da adição de AIB nas variáveis analisadas. Para massa fresca, área superficial, volume de raízes e número de raízes primárias as concentrações de AIB promoveram um aumento significativo nesses parâmetros morfológicos do sistema radicular, comparado com o tratamento controle (ausência de AIB). Para comprimento de raiz, na concentração de $1,0 \mathrm{mg} \mathrm{L}^{-1}$ de AIB observase valor superior estatisticamente em relação as demais concentrações $(15,96 \mathrm{~cm})$.

Um sistema radicular mais desenvolvido pode influenciar positivamente na absorção de nutrientes e de água. Quando este for limitado reduz a eficiência das atividades, afetando posteriormente a produção de biomassa. Microestacas que

Tabela 1. Valores de massa fresca $(\mathrm{MF})$, comprimento $(\mathrm{COM})$, área superficial (AS), volume (VOL) e número de raízes primárias $\left(\mathrm{N}^{\circ} \mathrm{R}\right)$ de microestacas de Tabernaemontana catharinensis A. DC., avaliadas aos 30 dias após a inoculação em concentrações de AIB.*Médias seguidas de mesma letra na coluna não diferem entre si pelo teste de Scott-Knott a 5\% de probabilidade.

\begin{tabular}{|c|c|c|c|c|c|}
\hline $\mathrm{AIB}\left(\mathrm{mg} \mathrm{L}^{-1}\right)$ & MF (mg) & $\mathrm{COM}(\mathrm{cm})$ & $\mathrm{AS}\left(\mathrm{cm}^{2}\right)$ & $\operatorname{VOL}\left(\mathrm{cm}^{3}\right)$ & $\mathrm{N}^{\circ} \mathrm{R}$ \\
\hline 0,0 & $18,7 \mathrm{~b}$ & $6,32 \mathrm{c}$ & $1,26 \mathrm{~b}$ & $0,021 \mathrm{~b}$ & $3,2 b$ \\
\hline 1,0 & $37,13 \mathrm{a}$ & $15,96 \mathrm{a}$ & $2,95 \mathrm{a}$ & $0,043 \mathrm{a}$ & $5,58 \mathrm{a}$ \\
\hline 2,0 & $30,08 \mathrm{a}$ & $11,94 \mathrm{~b}$ & $2,27 \mathrm{a}$ & $0,034 \mathrm{a}$ & $5,13 \mathrm{a}$ \\
\hline 4,0 & $35,33 \mathrm{a}$ & $13,31 \mathrm{~b}$ & $2,68 \mathrm{a}$ & $0,043 \mathrm{a}$ & $5,25 \mathrm{a}$ \\
\hline CV (\%) & 15,26 & 17,60 & 19,12 & 23,57 & 13,54 \\
\hline
\end{tabular}




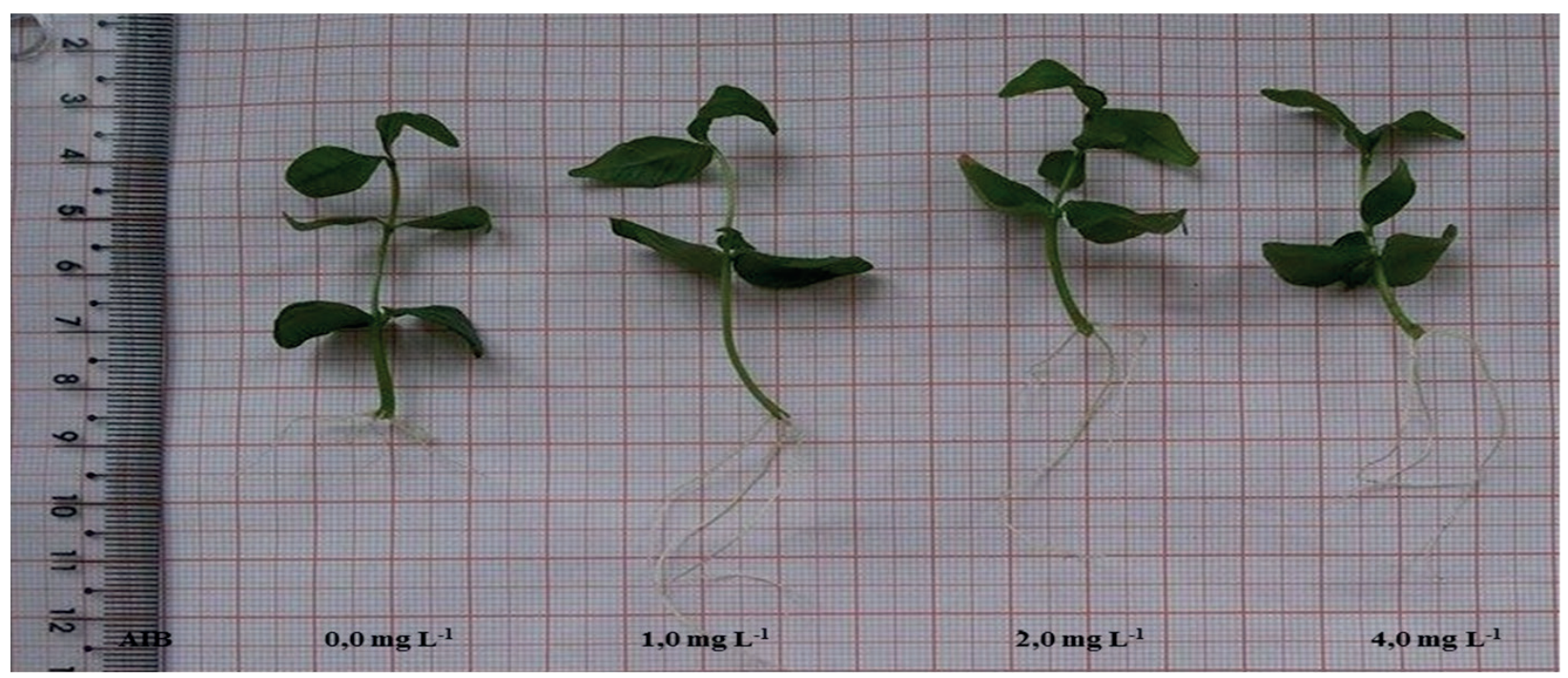

Fig. 4. Enraizamento de microestacas de Tabernaemontana catharinensis em diferentes concentrações de AIB aos 30 dias após a inoculação.

apresentam maior área superficial e número de raízes primárias são mais aptas a enfrentar condições de estresse hídrico, garantindo maiores taxas de sobrevivência. Além disso, maior número de raízes primárias aumenta o contato com regiões de absorção de água e de nutrientes. Segundo Maggio et al. (2007), a redução do volume radicular reduz a produção da biomassa fresca da raiz, reduzindo principalmente, a relação raiz/parte aérea, afetando o transporte dos sais do meio de cultivo para a parte aérea.

O crescimento acelerado das raízes pode ocorrer em função do estado nutricional da planta, mostrando que as microestacas são capazes de oferecer carboidratos, hormônios e outras substâncias necessárias ao alongamento das raízes, seja pela absorção do meio nutritivo e/ou pela produção através da fotossíntese (Dias et al. 2012). Segundo os autores, quanto mais bem nutrida à planta, maior o número de células produzidas pelos meristemas e mais longo será o eixo de crescimento. A formação de raízes adventícias é um processo que exige elevada quantidade de energia, por envolver a divisão celular, na qual as células predeterminadas alteram a rota morfogenética para formar os primórdios radiciais (Brondani et al. 2012). Segundo Haq et al. (2009), as reservas de carboidratos nas microestacas de Olea europaea constituíram a principal fonte de energia para a iniciação destes primórdios.

Em plantas obtidas in vitro, o sistema radicular mais vigoroso é considerado benéfico, uma vez que é importante para a posterior aclimatização ex vitro (Canto et al. 2004). A aclimatização é uma fase relevante e ao mesmo tempo crítica da micropropagação, podendo causar baixa sobrevivência das plantas, devido principalmente ao estresse que sofrem na passagem da condição in vitro para o ex vitro. Nesse processo de aclimatização, as plantas passam de um ambiente de baixa transpiração para ambiente de alta taxa de transpiração, de um estado heterotrófico para o estado autotrófico, de um meio com alta disponibilidade de nutrientes para um substrato com menor disponibilidade e de um estado asséptico para ficar sujeito ao ataque de microrganismos patogênicos (Grattapaglia \& Machado 1998). Todos esses fatores influenciam na sobrevivência das plantas.

Quando analisados os teores dos pigmentos fotossintéticos (Tab. 2), para os valores de chl $a$, chl total, relação chl $a / b$ e carotenoides não houve diferença estatística entre os tratamentos com ou sem AIB no meio de cultura. Com relação aos teores de $\operatorname{chl} b$, a presença de AIB no meio promoveu aumento nos mesmos, quando comparados com o valor obtido no tratamento sem AIB.

A auxina AIB tem efeito relevante na indução das raízes, pois este fitorregulador não só promove a divisão e o crescimento celular, como favorece o aumento da área superficial de raízes, e, consequentemente, a capacidade de absorção de água e nutrientes do meio de cultura, potencializando o fluxo de nitrogênio, fósforo, potássio,

Tabela 2. Valores médios da clorofila $a(\mathrm{Chl} a), b(\mathrm{Chl} b)$, total (Chltotal), relação entre clorofila $a$ e $b(\mathrm{Chl} a / b)$ e carotenoides em folhas de microestacas de Tabernaemontana catharinensis A. DC. expostas à diferentes concentrações de AIB aos 30 dias após a inoculação. MF refere-se à matéria fresca. *Médias seguidas de mesma letra na coluna não diferem entre si pelo teste de Scott-Knott a $5 \%$ de probabilidade.

\begin{tabular}{cccccc}
\hline $\mathrm{AIB}\left(\mathrm{mg} \mathrm{L}^{-1}\right)$ & $\begin{array}{c}\mathrm{Chl} a \\
\left(\mathrm{mg} \mathrm{g}^{-1} \mathrm{MF}\right)\end{array}$ & $\begin{array}{c}\mathrm{Chl} b \\
\left(\mathrm{mg} \mathrm{g}^{-1} \mathrm{MF}\right)\end{array}$ & $\begin{array}{c}\text { Chl total } \\
\left(\mathrm{mg} \mathrm{g}^{-1} \mathrm{MF}\right)\end{array}$ & $\begin{array}{c}\text { Chl } \\
a / b\end{array}$ & $\begin{array}{c}\text { Carotenoides } \\
\left(\mathrm{mg} \mathrm{g}^{-1} \mathrm{MF}\right)\end{array}$ \\
\hline 0,0 & $1,33 \mathrm{a}$ & $0,36 \mathrm{~b}$ & $1,69 \mathrm{a}$ & $3,74 \mathrm{a}$ & $0,36 \mathrm{a}$ \\
1,0 & $1,41 \mathrm{a}$ & $0,41 \mathrm{a}$ & $1,82 \mathrm{a}$ & $3,47 \mathrm{a}$ & $0,40 \mathrm{a}$ \\
2,0 & $1,54 \mathrm{a}$ & $0,44 \mathrm{a}$ & $1,98 \mathrm{a}$ & $3,47 \mathrm{a}$ & $0,43 \mathrm{a}$ \\
4,0 & $1,55 \mathrm{a}$ & $0,45 \mathrm{a}$ & $2,00 \mathrm{a}$ & $3,45 \mathrm{a}$ & $0,44 \mathrm{a}$ \\
$\mathrm{CV}(\%)$ & 11,31 & 10,50 & 10,86 & 5,91 & 9,92 \\
\hline
\end{tabular}


magnésio, cálcio e boro, importantes no processo de enraizamento (Ansari et al. 2004). Estes nutrientes também possuem papel fundamental no metabolismo vegetal por participar da biossíntese das clorofilas, especialmente o nitrogênio e o magnésio que compõem a estrutura química das mesmas (Streit et al. 2005), influenciando o conteúdo de clorofilas, especialmente clorofila $b$ nos tecidos juvenis (Martínez-Morales et al. 2003).

Os maiores teores de clorofila $b$ observados nos meios com AIB neste estudo são relevantes, pois este pigmento capta radiação luminosa de comprimento de onda diferente da clorofila $a$ e transfere a energia para esta, a qual efetivamente atua nas reações fotoquímicas da fotossíntese (Scalon et al. 2003). Uma maior taxa de absorção de radiação, promovida pela clorofila $b$, durante os últimos estádios da fase de enraizamento pode facilitar a aclimatização e aumentar a sobrevivência das plantas (Santana et al. 2008).

É possível evidenciar nas condições deste estudo que o uso do $\mathrm{GA}_{3}$ não promoveu maiores taxas de germinação em sementes de T. catharinensis, sendo a velocidade de germinação afetada negativamente em sementes expostas ao fitorregulador por um período maior (48h). A rizogênese em microestacas de $T$. catharinensis pode ser induzida sem a necessidade de AIB no meio de cultura. No entanto, o uso deste regulador de crescimento proporciona maior sistema radicular. Conclui-se que os parâmetros morfofisiológicos podem ser maximizados com a adição de auxina ao meio de cultura, demonstrando que o uso de AIB favorece a produção de mudas mais vigorosas a partir de microestacas de T. catharinensis.

\section{REFERÊNCIAS}

Ansari, S.A., Singh, S. \& Rani, A. 2004. Inorganic salts influence IAA ionization and adventitious rhizogenesis in Pongamia pinnata. Journal of Plant Physiology 161(1):117-120.

Aragão, C.A., Deon, M.D.I., Queiróz, M.A. \& Dantas, B.F. 2006. Germinação e vigor de sementes de melancia com diferentes ploidias submetidas a tratamentos pré-germinativos. Revista Brasileira de Sementes 28(3):82-86.

Arnon, D.I. 1949. Copper enzymes in isolated chloroplasts: polyphenoloxidases in Beta vulgaris. Plant Physiology 24(1):1-15.

Bélo, M., Barbosa, J.C., Pereira, P.S., Bertoni, B.W., Zingaretti, S.M. \& Belebonil, R.O. 2009. Avaliação do efeito bioinseticida dos extratos de Tabernaemontana catharinensis A. DC. (Apocynaceae) e Zeyheria montana Mart. (Bignoniaceae) sobre a mosca Zaprionus indianus (Díptera: Drosophilidae) (Gupta, 1970). Revista Brasileira de Biociências 7(3):235-239.

Borges, S.R., Xavier, A., Oliveira, L.S., Melo, L.A \& Rosado, A.M. 2011. Enraizamento de miniestacas de clones híbridos de Eucalyptus globulus. Revista Árvore 35(3):425-434.

Braun, H., Lopes, J.C., Souza, L.T., Schmildt, E.R., Cavatte, R.P.Q. \& Cavatte, P.C. 2010. Germinação in vitro de sementes de beterraba tratadas com ácido giberélico em diferentes concentrações de sacarose no meio de cultura. Semina: Ciência Agrárias 31(3):539-546.

Brondani, G.E., Hoffmann, M.E., Gonçalves, A.N \& Almeida, M. 2012. Determinação do teor de carboidratos em minicepas de Eucalyptus benthamii. Journal of Biotechnology and Biodiversity 3(1):51- 60 .

Bortolini, M.F., Mayer, J.L.S., Ribas, C.Z., Koehler, H.S. \& Carpanezzi, A.A. 2009. Enraizamento de estacas caulinares de quarto espécies do gênero Tibouchina Aubl. (Melastomataceae Juss.). Revista Brasileira de Horticultura Ornamental 14(2):187-192.
Canto, A.M.M.E., Souza, F.V.D., Costa, M.A.C., Souza, A.S., Ledo, C.A.S. \& Cabral, J.R.S. 2004. Conservação in vitro de germoplasma de abacaxi tratado com paclobutrazol. Pesquisa Agropecuária Brasileira 39(7):717-720.

Castro, P.R.E. \& Vieira, E.L. 2003. Ação de bioestimulante na cultura do feijoeiro. In Feijão irrigado: tecnologia e produtividade (A.L. Fancelli \& V. Dourado Neto, eds). Escola Superior de Agricultura Luiz de Queiroz, Piracicaba, p. 73-100.

Dalastra, I.M., Pio, R., Entelmann, F.A., Werle, T., Uliana, M.B. \& Scarpare Filho, J.A. 2010. Germinação de sementes de nogueiramacadâmia submetidas à incisão e imersão em ácido giberélico. Ciência e Agrotecnologia 34(3):641-645.

Dias, P.C., Xavier, A., Oliveira, L.S., Paiva, H.N. \& Correia, A.C.G. 2012. Propagação vegetativa de progênies de meios-irmãos de angico-vermelho (Anadenanthera macrocarpa (Benth) Brenan) por miniestaquia. Revista Árvore 36(3):389-399.

Ferreira, D.F. 2008. SISVAR: um programa para análises estatísticas e ensino de estatística. Revista Symposium 6(2):36-41.

Ferreira, J.T.B., Corrêa, A.G. \& Vieira, P.C. 2001. Produtos Naturais no Controle de Insetos. Editora da Universidade Federal de São Carlos, São Carlos. 176 p.

Ford, Y.Y., Bonham, E.C., Cameron, R.W.F., Blake, P.S., Judd, H.L \& Harrison-Murray, R.S. 2002. Adventitious rooting: examining the role of auxin in easy and a difficult-to-root plant. Plant Growth Regulation 36(2):149-159.

Galdiano Júnior, R.F., Mantovani, C., Pivetta, F.L. \& Lemos, E.G.M. 2012. Crescimento in vitro e aclimatização de Cattleya loddigesii Lindley (Orchidaceae) com carvão ativado sob dois espectros luminosos. Ciência Rural 42(5):801-807.

Grattapaglia, D. \& Machado, M.A. 1998. Micropropagação. In Cultura de tecidos e transformação genética de plantas (A.C. Torres, L.S. Caldas \& J.A. Buso, eds). Empresa Brasileira de Pesquisa Agropecuária, Brasília, p. 183-260.

Haq, I.U., Ahmad, T., Hafiz, I.A. \& Abbasi, N.A. 2009. Influence of microcutting sizes and IBA concentrations on in vitro rooting of olive cv. 'Dolce Agogia'. Pakistan Journal Botany 41(3):1213-1222.

Labouriau, L.G. \& Valadares, M.E.B. 1976. On the germination of seeds Calotropis procera (Ait.) Ait.f. Anais da Academia Brasileira de Ciências 48(2):263-284.

Maggio, A., Raimondi, G., Martino, A. \& Pascale, S. 2007. Salt stress response in tomato beyond the salinity tolerance threshold. Environmental and Experimental Botany 59(3):276-282.

Maguire, J.D. 1962. Speed of germination aid in selection and evaluation for seedling emergence and vigor. Crop Science 2(1):176-177.

Martínez-Morales, L.J., Soto-Urzúa, L., Baca, B.E. \& Sánchez-Ahédo, J.A. 2003. Indole-3-butyric acid (IBA) production in culture medium by wild strain Azospirillum brasilense. FEMS microbiology Letter 228(2):167-173.

Murashige, T. \& Skoog, F. 1962. A revised medium for rapid growth and bio assays with tobacco tissue cultures. Physiologia Plantarum 15(3):473-497.

Nascimento, P.K.V., Franco, E.T H. \& Frassetto, E.G. 2007. Desinfestação e Germinação in vitro de sementes de Parapiptadenia rigida Bentham (Brenam). Revista Brasileira de Biociências 5(2):141-143.

Neto, M.P., Dantas, A.C.V.L., Vieira, E.L. \& Almeida, V.O. 2007. Germinação de sementes de jenipapeiro submetidas à pré-embebição em regulador e estimulante vegetal. Ciência Agrotécnica 31(3):693698.

Noleto, L.G. \& Silveira, C.E.S. 2004. Micropropagação de copaíba. Biotecnologia Ciência e Desenvolvimento. Disponível em: http:// www.biotecnologia.com.br/revista/bio33/copaiba.pdf. Acessado em 01.02.2016.

Pereira, C.G., Leal, P.F., Sato, D.N. \& Meireles, M.A. 2005. Antioxidant and antimycobacterial activities of Tabernaemontana catharinensis extracts obtained by supercritical $\mathrm{CO}_{2}+$ cosolvent. Journal of Medicinal Food 8(4):53-538.

Pereira, P.S., França, S.C., Oliveira, P.V.A., Breves, C.M.S., Pereira, S.I.V., Sampaio, S.V., Nomizo, A. \& Dias, D.A. 2008. Chemical constituents from Tabernaemontana catharinensis root bark: a brief NMR review of indole alkaloids and in vitro cytotoxicity. Química Nova 31(1):20-24. 
Piana, M., Boligon, A.A., Brum, T.F., Zadra, M., Belke, B.V., Froeder, A.L.F., Frohlich, J.K., Nunes, L.T., Pappis, L., Boligon, A.A. \& Athayde, M.L. 2014. Phytochemical analysis and antioxidante capacity of Tabernaemontana catharinensis A. DC. Fruits and branches. Anais da Academia Brasileira de Ciências 86(2):881888.

Quinet, C.G.P. \& Andreata, R.H.P. 2005. Estudo Taxonômico e Morfológico das Espécies de Apocynaceae Adans na Reserva Rio das Pedras, Município de Mangaratiba, Rio de Janeiro, Brasil. Pesquisa Botânica 56:13-74.

Rocha, S.C., Quorim, M., Ribas, L.L.F. \& Koehler, H.S. 2007. Micropropagação de Cabralea canjerana. Revista Árvore 31(1):4350 .

Santana, J.R.F., Paiva, R., Resende, R.K.S., Castro, E.M., Pereira, F.D. \& Oliveira, L.M. 2008. Estímulo do comportamento fotoautotrófico durante o enraizamento in vitro de Annona glabra L., II. Aspectos da anatomia da folha antes da aclimatização. Ciência e Agrotecnologia 32(2):640-644.

Scalon, S.P.Q., Mussury, R.M., Scalon Filho, H., Francelino, C.S.F. \& Florencio, D.K.A. 2006. Armazenamento e tratamento prégerminativos em sementes de jacarandá (Jacaranda cuspidifolia Mart.). Revista Árvore 30(2):529-536.

Scalon, S.P.Q., Mussury, R.M., Rigoni, M.R. \& Scalon Filho, H. 2003.
Crescimento inicial de mudas de Bombacopsis glabra (Pasq.) A. Robyns sob condição de sombreamento. Revista Árvore 27(6):753758.

Silva, R.L., Oliveira, M.L., Monte, M.A. \& Xavier, A. 2010. Propagação clonal de guanandi (Calophyllum brasiliense) por miniestaquia. Agronomía Costarricense 34(1):99-104.

Sobral, M. \& Jarenkow, J.A., Brack, P., Irgang, B.E., Larocca, J. \& Rodrigues, R.S. 2006. Flora Arbórea e Arborescente do Rio Grande Do Sul, Brasil. Rima/Novo Ambiente, São Carlos. 350 p.

Sousa, H.U., Ramos, J.D., Pasqual, M. \& Ferreira, E.A. 2002. Efeito do ácido giberélico sobre a germinação de porta-enxertos cítricos. Revista Brasileira de Fruticultura 24(2):496-499.

Stein, V.C., Paiva, R., Soares, F P., Nogueira, R.C., Silva, L.C., \& Emrich, E. 2007. Germinação in vitro e ex vitro de Inga vera Willd. subsp. affinis (DC.) T. D. Penn. Ciência e Agrotecnologia 31(6):1702-1708.

Streit, N.M., Canterle, L.P., Canto, M.W. \& Hecktheuer, L.H.H. 2005. As clorofilas. Ciência Rural 35(1):748-755.

Vicente, M.A.A., Almeida, W.A.B. \& Carvalho, Z.S. 2009. Multiplicação in vitro e aclimatação de Vernonia condensata Baker. Revista Brasileira de Plantas Medicinais 11(2):176-183.

Xavier, A., Wendling, I. \& Silva, R.L. 2009. Silvicultura clonal: princípios e técnicas. Universidade Federal de Viçosa, Viçosa. 272 p. 